Article

\title{
Effect of Football Shoe Collar Type on Ankle Biomechanics and Dynamic Stability during Anterior and Lateral Single-Leg Jump Landings
}

\author{
Yunqi Tang ${ }^{1,2}{ }^{\oplus}$, Zhikang Wang ${ }^{2}$, Yifan Zhang ${ }^{2}$, Shuqi Zhang ${ }^{3}$, Shutao Wei ${ }^{4}$, Jiahao Pan ${ }^{4}$ and \\ Yu Liu ${ }^{1, *}$ \\ 1 Key Laboratory of Exercise and Health Sciences of the Ministry of Education, Shanghai University of Sport, \\ Shanghai 200438, China; tangyunqi@sust.edu.cn \\ 2 College of Art \& Design, Shaanxi University of Science \& Technology, Xi'an 710021, China; \\ 1710073@sust.edu.cn (Z.W.); 1710035@sust.edu.cn (Y.Z.) \\ 3 Department of Kinesiology \& Center for Orthopaedic \& Biomechanics Research, Boise State University, \\ Boise, ID 83725, USA; shuqizhang@boisestate.edu \\ $4 \quad 361^{\circ}$ (CHINA) CO., LTD., Xiamen 361009, China; st.wei@361sport.com (S.W.); toby881012@gmail.com (J.P.) \\ * Correspondence: yuliu@sus.edu.cn; Tel.: +86-21-65507860
}

Received: 13 March 2020; Accepted: 5 May 2020; Published: 13 May 2020

\begin{abstract}
In this study, we investigated the effects of football shoes with different collar heights on ankle biomechanics and dynamic postural stability. Fifteen healthy college football players performed anterior and lateral single-leg jump landings when wearing high collar, elastic collar, or low collar football shoes. The kinematics of lower limbs and ground reaction forces were collected by simultaneously using a stereo-photogrammetric system with markers (Vicon) and a force plate (Kistler). During the anterior single-leg jump landing, a high collar shoe resulted in a significantly smaller ankle dorsiflexion range of motion (ROM), compared to both elastic $(p=0.031, \mathrm{dz}=0.511)$ and low collar $(p=0.043, \mathrm{dz}=0.446)$ types, while also presenting lower total ankle sagittal ROM, compared to the low collar type $(p=0.023, \mathrm{dz}=0.756)$. Ankle joint stiffness was significantly greater for the high collar, compared to the elastic collar $(p=0.003, \mathrm{dz}=0.629)$ and low collar $(p=0.030$, $\mathrm{dz}=1.040$ ). Medial-lateral stability was significantly improved with the high collar, compared to the low collar $(p=0.001, \mathrm{dz}=1.232)$. During the lateral single-leg jump landing, ankle inversion ROM $(p=0.028, \mathrm{dz}=0.615)$ and total ankle frontal $\operatorname{ROM}(p=0.019, \mathrm{dz}=0.873)$ were significantly smaller for the high collar, compared to the elastic collar. The high collar also resulted in a significantly smaller total ankle sagittal ROM, compared to the low collar $(p=0.001, \mathrm{dz}=0.634)$. Therefore, the high collar shoe should be effective in decreasing the amount of ROM and increasing the dynamic stability, leading to high ankle joint stiffness due to differences in design and material characteristics of the collar types.
\end{abstract}

Keywords: collar height; kinematics; kinetics; dynamic stability; ankle injury

\section{Introduction}

Football is the most popular sport in the world, has the largest number of participants, and is associated with a high risk of injury at the professional, amateur, and youth levels during practices and matches [1-5]. It is estimated that somewhere between 13 and 35 players get injured every 1000 competitive hours. The most common incidence of injuries occurs in the lower limbs, mostly ankle sprains [1,5,6]. Dvorak et al. studied injury incidences in the 2010 International Federation of Association Football World Cup. They found that ankle sprains were the most prevalent injury in practices or matches [6]. The impacts of ankle sprains can be severe and include considerable 
medical expenses, decreased fitness or endurance levels, and missed matches. Furthermore, a common complication of ankle sprains is chronic ankle instability, which results in episodes of the ankle giving way, recurrent sprains, and persistent symptoms such as pain, swelling, limited motion, weakness, and diminished self-reported function. This includes functional and mechanical impairments in isolation, or both [7].

In order to lower football injury risk, shoe manufacturers have attempted to design different cleat configurations that can handle a variety of field conditions, such as turf or grass. In an early study, researchers reported that decreasing the number of cleats and their size may reduce the risk of knee injury [8]. Queen et al. determined that turf cleats could decrease the pressure and force beneath the forefoot, compared to other types of cleats that might minimize metatarsal injury risk on grass [9]. However, Torg et al. examined the mechanical properties of rotational torsion resistance to explain the relation between turf shoes and surface conditions at five temperatures, suggesting that only flat turf football shoes could lower the sprain risk incidence under all conditions [10]. Adjusting cleat configurations could potentially minimize the risk of injuries such as knee sprains and stress fractures on specific field conditions. However, at present, no clear experimental evidence exists to determine the positive effect of cleat configurations on improved ankle stability or decreased ankle sprains.

Increased ankle stability and the prevention of ankle sprains by increasing the shoe collar height have been examined for basketball shoes [11-15]. High collar basketball shoes exhibit a smaller ankle inversion range of motion (ROM), smaller ankle inversion and external rotation at initial contact, and smaller peak inversion velocity, compared to low collar shoes, but no significant difference in kinetic parameters during side-step cutting are observed [11,12]. During jumping tasks, research has revealed that ankle joints show a smaller peak plantarflexion moment and power when wearing basketball shoes with high collars, compared to low collars [13]. According to other research, high collar basketball shoes result in delayed pre-activation timing and decreased amplitude of muscle activity [14]. Therefore, high collar basketball shoes are one factor used to reduce injury potential [16].

Based on the experience with basketball shoes, similar footwear technology has been implemented in football shoes in an attempt to mitigate injury risk. Researchers have observed the ankle inversion between high and low collar football shoes using an inversion platform, which can be rotated $35^{\circ}$ to induce a sudden ankle inversion [17]. This research has indicated that high collar shoes significantly reduce the amount and rate of inversion. Additionally, using an arthrometer foot plate, researchers have found that high collar shoes are more effective in decreasing inversion ROM and velocity [18]. However, the research method employed in these previous studies does not accurately portray real-world practices and matches when only the ankle inversion is available. Additionally, although the peak ankle plantarflexion moment and power are significantly smaller in high collar, compared to low collar basketball shoes during landing jumps [13], knowledge of the effects of football shoe collar types on ankle dorsiflexion/plantar flexion movement is currently limited. Furthermore, according to previous studies, around $31 \%$ to $46 \%$ of football injuries, especially for the knee and ankle, are induced by losing balance or inducing a sprain after landing [19,20]. Hence, for football shoes, questions remain regarding how ankle kinematics and kinetics behave in both dorsiflexion-plantarflexion and inversion-eversion dynamic movements when performing jumping and landing maneuvers.

It should be noted that postural stability has been used to examine the risk of ankle sprain [21,22], and a deficiency in postural stability could play a significant role in increasing ankle sprain risk [20]. A study has found that high collar boots have smaller postural sway, compared to low collar boots, and thereby collar height might have a positive effect on postural control [23]. In a recent study, however, a high collar football shoe did not enhance static postural stability, compared to a low collar shoe [18]. Thus, limited research is available regarding the effects of shoe collars on postural stability. Evidence from a psychological study shows that elastic ankle taping or stiff ankle bracing provides beneficial effects by increasing the feeling of confidence and stability during dynamic-balance tasks [24]. However, direct evidence is conflicting on the beneficial impact on dynamic balance [25-28]. The lack of consistent findings may be due to a lack of measuring more sensitive parameters. The dynamic postural 
stability index (DPSI) measures three directional components of the ground reaction force during single-leg jump landings. Furthermore, DPSI and its directional components can detect differences in dynamic stability in different football collar types [29]. Therefore, DPSI provides a measure of dynamic stability that has high precision and reliability [30].

Determining the effect of high collar football shoes on ankle biomechanics and DPSI during single-leg jump landings might provide further insight into the biomechanics and dynamic stability of playing football. The purpose of the study aims to determine differences in shoe collar types (i.e., low collar, elastic collar, and high collar) on ankle biomechanics and DPSI during anterior and lateral single-leg jump landings. Our first hypothesis was that smaller ankle ROM, moment, and joint stiffness would result from the high collar football shoe, compared to the elastic or low collar shoes, in both tasks. Our second hypothesis was that dynamic stability would improve when wearing a high collar football shoe, compared to an elastic or low collar shoe, in both tasks.

\section{Materials and Methods}

\subsection{Participants}

Fifteen healthy male college football players (age: $21.2 \pm 2.0$ years; height: $172.4 \pm 5.3 \mathrm{~cm}$; body mass: $66.5 \pm 9.7 \mathrm{~kg}$ ) were recruited in this study. The inclusion criteria were (1) at least three years football training experience; (2) foot length of U.S. size 8 for heel-to-toe length; (3) right leg dominant (preferred for kicking); (4) not having sustained a lower limb injury within the past 12 months, including ankle sprain, fractures, or surgeries; and (5) no history of neural or vestibular diseases. The University Ethics Board approved this study, and all participants gave written informed consent before they participated in this study.

\subsection{Equipment}

Three commercially available football shoes (U.S. size 8, Vapor Untouchable 3; Nike, Portland, OR, USA), which are very popular for football players, were tested in the current study. All shoes were built on the same shoe platform and had identical lightweight upper sections, carbon fiber, thermoplastic polyurethane plates, and cleats, but different shoe collar types: high collar (mass: $300 \mathrm{~g}$; collar height: $70 \mathrm{~mm}$; material: high intensity knitted fabric), elastic collar (mass: $310 \mathrm{~g}$; collar height: $35 \mathrm{~mm}$; material: low intensity knitted fabric), and low collar (mass: $300 \mathrm{~g}$; collar height: $0 \mathrm{~mm}$, material: nil) (Figure 1).

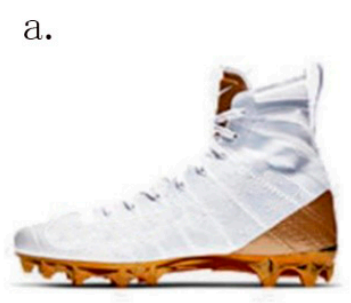

b.

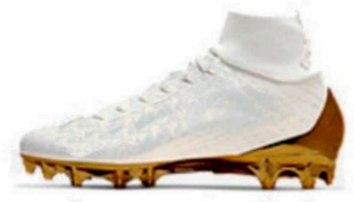

c.

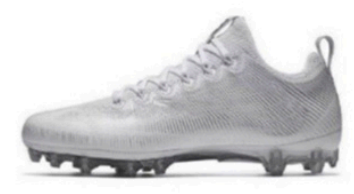

Figure 1. Football shoes used in the current study. (a) high collar shoe, (b) elastic collar shoe, (c) low collar shoe.

The testing environment was an indoor artificial turf-top football ground. The three-dimensional kinematics were measured using a ten-camera Vicon Vantage motion capture system (Vantage 8; Vicon, Oxford, UK), which was arranged around the artificial turf football ground, at a sampling rate of $200 \mathrm{~Hz}$. These cameras are widely used to capture motion trajectory in sports science and biomechanics to optimize human movement [31,32]. The ground reaction force, which was measured for the dominant lower limb, was collected simultaneously using a $600 \times 900 \mathrm{~mm}$ force plate $(9287 \mathrm{C}$; Kistler, Winterthur, Switzerland), which was recessed in the middle of the artificial turf football ground, at a sampling 
rate of $1000 \mathrm{~Hz}$. The force plate was also used to record the forces exerted by the foot when standing, walking, or running [31,32]. A $900 \times 600 \times 10 \mathrm{~mm}$ artificial turf cover was fixed on the surface of the force plate through screws at each corner (Figure 2). The kinematics and kinetic data were collected and synchronized using a Nexus Lock (Lock +; Vicon, Oxford, UK) with Nexus software (Nexus 2.6.1; Oxford, UK). The Nexus Lock is Vicon's control box for connecting, integrating, and synchronizing third-party devices with the Vicon motion capture system.

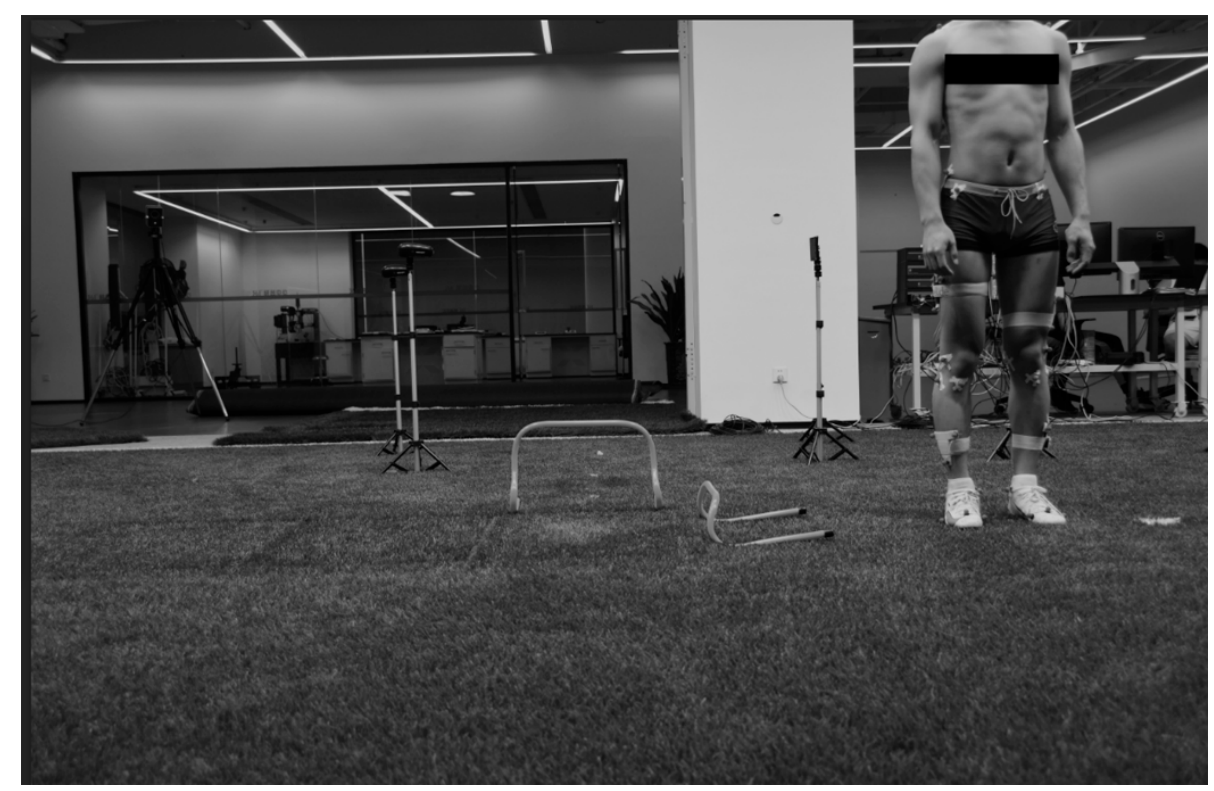

Figure 2. Experimental setup.

Thirty-six retroreflective markers (diameter: $14 \mathrm{~mm}$ ) were attached to the lower limbs using bio-adhesive tapes. The reflective markers were placed on both the right and left limbs of the iliac crest; anterior superior iliac spine; posterior superior iliac spine; lateral/medial prominence of the lateral femora epicondyle; proximal tip of the head of the fibula; anterior border of the tibial tuberosity; lateral/medial prominence of the lateral malleolus; dorsal margin of the first, second, and fifth metatarsal head; and four four-marker rigid clusters were attached bilaterally onto the thigh and shank.

\subsection{Protocol}

Each participant performed two tasks, anterior and lateral single-leg jump landings, in one day. Therefore, participants were asked to implement either the anterior single-leg jump landing or the lateral single-leg jump landing, while wearing either low, elastic, or high collar football shoes. All of the tasks were first randomized, and then the shoe order was randomized. Prior to data collection, anatomical and tracking reflective markers were placed on the lower limbs, according to the Istituto Ortopedico Rizzoli (IOR) lower limb model [31]. Meanwhile, the shoelaces were tied by an experimenter and the same type of sport socks were worn, in order to avoid the effects of various shoelaces and socks on the results. Participants were provided five practice trials for each task, to become familiar with the reflective markers and tasks. The anterior and lateral single-leg jump landings were normalized by jump distance according to body height, which was $40 \%$ and $33 \%$ of body height, respectively [33,34]. Additionally, $30 \mathrm{~cm}$ and $15 \mathrm{~cm}$ hurdles were placed at $10 \mathrm{~cm}$ from the edge of the force plate in anterior and lateral single-leg jump landings, respectively. During data collection, participants were positioned at a normalized distance, then they jumped onto the center of the force plate and landed on their dominant leg after receiving the "start" signal from the researcher. For each condition, each participant was required to stabilize as quickly as possible, place their hands on their waist during landing, and remain motionless on the landing leg for $10 \mathrm{~s}$. Trials were discarded 
and repeated for the following reasons: (1) moving the foot before jumping, (2) touching or collapsing the hurdle during jumping, or (3) losing balance or removing hands from the waist during landing. To prevent fatigue, $2 \mathrm{~min}$ and $5 \mathrm{~min}$ breaks were provided between trials and tasks. Trials of each condition were collected for three successful jump landings tasks.

\subsection{Data Analysis}

Visual3D software (C-motion, Inc.; Germantown, MD, USA) was used to analyze the marker positions and force plate data, which were filtered with a low-pass Butterworth filter with cut-off frequencies of $14 \mathrm{~Hz}$ and $50 \mathrm{~Hz}$, respectively. The ankle joint angle was defined using the segment coordinate system for the virtual foot segment, which set the ankle joint angle to zero degrees in the static standing, to be aligned with the segment coordinate system for the shank. The ankle joint moment was calculated using Newton-Euler inverse dynamics with the proximal segment of the shank as the reference segment, which was normalized to each participant's body mass. Ankle joint stiffness was calculated as the change in ankle joint moment divided by the change in ankle joint angle from initial contact to peak dorsiflexion [35].

The DPSI is the composite of the vertical (VSI), anteroposterior (APSI), and medial-lateral (MLSI) components, and was computed following the method of Wikstrom et al. [30] using the customized Visual3D software. The square root of the mean square deviation of force, which was the fluctuation from the baseline along each axis of the force plate, was calculated. The APSI and MLSI were assessed using the fluctuations from 0 , and the VSI was calculated using the fluctuation from the subject's body weight. The square root of the sum of the squares of APSI, MLSI, and VSI constituted total DPSI.

These variables were calculated using the first $3 \mathrm{~s}$ following initial contact, identified as the force threshold exceeding $10 \mathrm{~N}$. The time interval of $3 \mathrm{~s}$ is recommended by Wikstrom et al. for studies of sports performance [36]. For anterior single-leg jump landings, the variables of interest included: (1) ankle dorsiflexion ROM, which refers to the total ankle dorsiflexion excursion; (2) ankle eversion ROM, which refers to the total ankle eversion excursion; (3) total ankle ROM in the sagittal and frontal planes, which refers to the total angle changes in the ankle joint in both planes; (4) peak ankle plantarflexion moment, which refers to the maximum plantarflexion moment; (5) peak ankle inversion moment, which refers to the maximum inversion moment; (6) ankle joint stiffness; and (7) APSI, MLSI, VSI, and DPSI, which refer to the assessments of dynamic postural stability. For lateral single-leg jump landings, the variables of interest were similar to the anterior single-leg jump landing, but with two extra variables: (1) ankle inversion ROM, which is the total ankle inversion excursion; and (2) peak eversion moment, which is the maximum eversion moment. The variables of interest are listed in Tables 1 and 2.

Table 1. Mean (standard deviation) of biomechanical variables and pairwise post hoc $p$-value (Cohen's $\mathrm{dz}$ ) in ankle joint during tasks in the high-, elastic-, and low collar shoe conditions.

\begin{tabular}{|c|c|c|c|c|c|c|}
\hline Variables & \multicolumn{3}{|c|}{ Shoe Collar Condition } & \multicolumn{3}{|c|}{ Pairwise Post Hoc } \\
\hline \multicolumn{7}{|c|}{ Anterior single-leg jump landing } \\
\hline Eversion $\mathrm{ROM}\left({ }^{\circ}\right)$ & $10.47(3.48)$ & $11.72(3.43)$ & $10.09(2.76)$ & $0.286(0.362)$ & $0.691(0.121)$ & $0.030(0.524)$ \\
\hline Peak plantarflexion moment $(\mathrm{Nm} / \mathrm{kg})$ & $2.38(0.38)$ & $2.21(0.36)$ & $2.24(0.35)$ & $0.095(0.459)$ & $0.789(0.383)$ & $1.000(0.084)$ \\
\hline Peak inversion moment $(\mathrm{Nm} / \mathrm{kg})$ & $0.48(0.24)$ & $0.58(0.43)$ & $0.51(0.31)$ & $0.442(0.287)$ & $0.696(0.108)$ & $0.437(0.187)$ \\
\hline Dorsiflexion ROM $\left(^{\circ}\right)$ & $18.11(5.13)$ & $20.50(3.50)$ & $20.62(2.39)$ & $0.058(0.544)$ & $0.059(0.627)$ & $0.907(0.040)$ \\
\hline Eversion $\mathrm{ROM}\left({ }^{\circ}\right)$ & $8.85(3.13)$ & $11.04(4.29)$ & $9.20(4.74)$ & $0.005(0.583)$ & $0.752(0.087)$ & $0.116(0.407)$ \\
\hline Inversion $\operatorname{ROM}\left({ }^{\circ}\right) *$ & $12.10(3.15)$ & $15.00(5.88)$ & $12.97(4.25)$ & $0.028(0.615)$ & $0.323(0.233)$ & $0.054(0.396)$ \\
\hline Peak plantarflexion moment $(\mathrm{Nm} / \mathrm{kg})$ & $2.42(0.36)$ & $2.39(0.49)$ & $2.51(0.48)$ & $1.000(0.070)$ & $1.000(0.212)$ & $0.785(0.247)$ \\
\hline Peak inversion moment $(\mathrm{Nm} / \mathrm{kg})$ & $0.29(0.21)$ & $0.37(0.32)$ & $0.31(0.21)$ & $0.402(0.296)$ & $0.704(0.095)$ & $0.496(0.222)$ \\
\hline
\end{tabular}

Note. ${ }^{*}$ represents a significant difference within a subject factor. High (H), Elastic (E), and Low (L) represent three football shoe conditions: high collar, elastic collar, and low collar, respectively. 
Table 2. Mean (standard deviation) of dynamic postural stability index and pairwise post hoc $p$-value (Cohen's dz) during tasks in the high-, elastic-, and low collar shoe conditions.

\begin{tabular}{|c|c|c|c|c|c|c|}
\hline \multirow{2}{*}{ Variables } & \multicolumn{3}{|c|}{ Shoe Collar Condition } & \multicolumn{3}{|c|}{ Pairwise Post Hoc } \\
\hline & High & Elastic & Low & H vs. E & H vs. $L$ & E vs. L \\
\hline \multicolumn{7}{|c|}{ Anterior single-leg jump landing } \\
\hline APSI & $0.17(0.014)$ & $0.17(0.022)$ & $0.17(0.024)$ & $1.000(0.101)$ & $1.000(0.131)$ & $0.714(0.194)$ \\
\hline MLSI * & $0.039(0.004)$ & $0.040(0.007)$ & $0.045(0.006)$ & $1.000(0.204)$ & $0.001(1.232)$ & $0.051(0.116)$ \\
\hline VSI & $0.42(0.049)$ & $0.42(0.050)$ & $0.43(0.059)$ & $1.000(0.035)$ & $0.387(0.234)$ & $0.312(0.263)$ \\
\hline DPSI & $0.45(0.045)$ & $0.45(0.050)$ & $0.46(0.058)$ & $1.000(0.016)$ & $0.569(0.220)$ & $0.526(0.225)$ \\
\hline \multicolumn{7}{|c|}{ Lateral single-leg jump landing } \\
\hline APSI & $0.064(0.007)$ & $0.063(0.007)$ & $0.063(0.010)$ & $1.000(0.116)$ & $1.000(0.087)$ & $1.000(0.007)$ \\
\hline MLSI * & $0.14(0.009)$ & $0.14(0.009)$ & $0.14(0.012)$ & $0.982(0.203)$ & $0.359(0.411)$ & $0.060(0.588)$ \\
\hline VSI & $0.39(0.038)$ & $0.38(0.049)$ & $0.38(0.048)$ & $1.000(0.078)$ & $1.000(0.159)$ & $1.000(0.071)$ \\
\hline DPSI & $0.42(0.038)$ & $0.41(0.047)$ & $0.40(0.060)$ & $1.000(0.058)$ & $0.547(0.340)$ & $0.614(0.270)$ \\
\hline
\end{tabular}

Note. * represents a significant difference within a subject factor. High (H), Elastic (E), and Low (L) represent three football shoe conditions: high collar, elastic collar, and low collar, respectively.

\subsection{Statistical Analyses}

The residual of each dependent variable was assessed for normality using a one-sample Kolmogorov-Smirnov test $(\alpha=0.05)$. Differences between shoe conditions were examined using two (for anterior and lateral single-leg jump landings) one-way within-subject analyses of variance (ANOVA). Pairwise post hoc analyses were conducted to assess significant differences in the main effects. Wilks's $\Lambda$ and effect size (np2) were calculated, and Cohen's dz effect sizes were used to interpret the effect of pairwise comparisons. An alpha level of 0.05 was used for statistical analysis. SPSS (19.0, IBM Inc.; Chicago, IL, USA) was used to conduct all statistical analyses.

\section{Results}

All the variables of interest were normally distributed. Mean (standard deviation) values of each ankle biomechanical variable and the stability index for each collar type, which were estimated intra-subject first and then inter-subject, are shown in Tables 1 and 2, respectively.

\subsection{Anterior Single-Leg Jump Landing}

The result of the ANOVA indicated a significant shoe effect on dorsiflexion ROM $\left(\mathrm{F}_{2,28}=3.829\right.$, $p=0.035$, Wilks's $\left.\Lambda=0.675, \eta p^{2}=0.639\right)$, total ROM in the sagittal plane $\left(F_{2,28}=7.554, p=0.006\right.$, Wilks's $\left.\Lambda=0.590, \eta p^{2}=0.854\right)$, ankle joint stiffness $\left(F_{2,28}=7.431, p=0.009\right.$, Wilks's $\left.\Lambda=0.445, \eta p^{2}=0.810\right)$, and MLSI $\left(\mathrm{F}_{2,28}=7.418, p=0.004\right.$, Wilks's $\left.\Lambda=0.382, \eta \mathrm{p}^{2}=0.884\right)$. Post hoc pairwise tests indicated that the high collar resulted in a significantly smaller dorsiflexion ROM, compared to the elastic collar $(p=0.031, \mathrm{dz}=0.511)$ and low collar $(p=0.043, \mathrm{dz}=0.446)$ (Table 1$)$, while a significantly smaller total ROM was observed for the high collar, compared to the low collar $(p=0.023, \mathrm{dz}=0.756)$ in the sagittal plane (Figure 3). The ankle joint stiffness was significantly larger for the high collar, compared to the low collar $(p=0.030, \mathrm{dz}=1.040)$ and elastic collar $(p=0.003, \mathrm{dz}=0.629)$ (Figure 4). MLSI was significantly smaller for the shoe with the high collar, compared to the low collar $(p=0.004, \mathrm{dz}=1.232)$ (Table 2). No other main effects of shoe conditions were detected (Tables 1 and 2). 


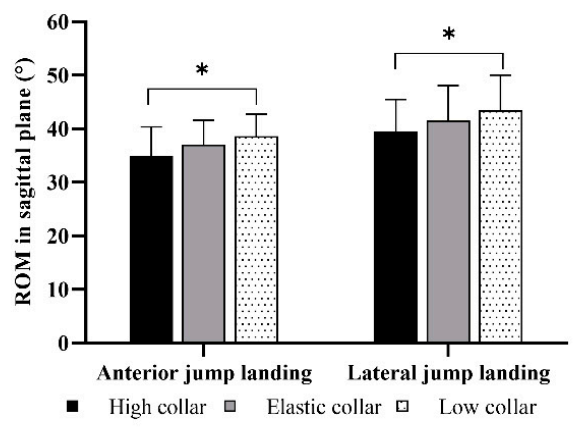

(a)

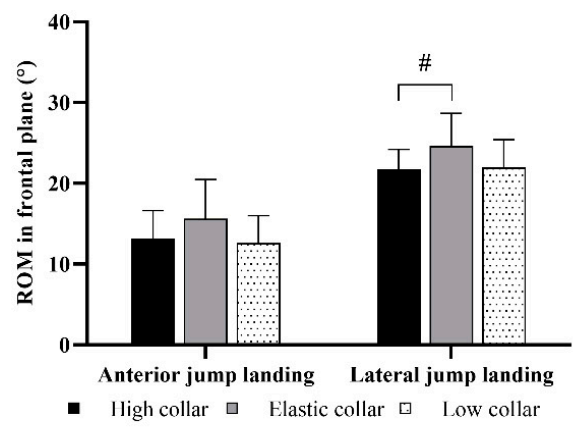

(b)

Figure 3. Range of motion (ROM) in the sagittal (a) and frontal (b) planes for both anterior and lateral jump landings in three shoe conditions: high collar, elastic collar, and low collar. * indicates a significant pairwise difference between the high collar and low collar; \# indicates a significant pairwise difference between the high collar and elastic collar.

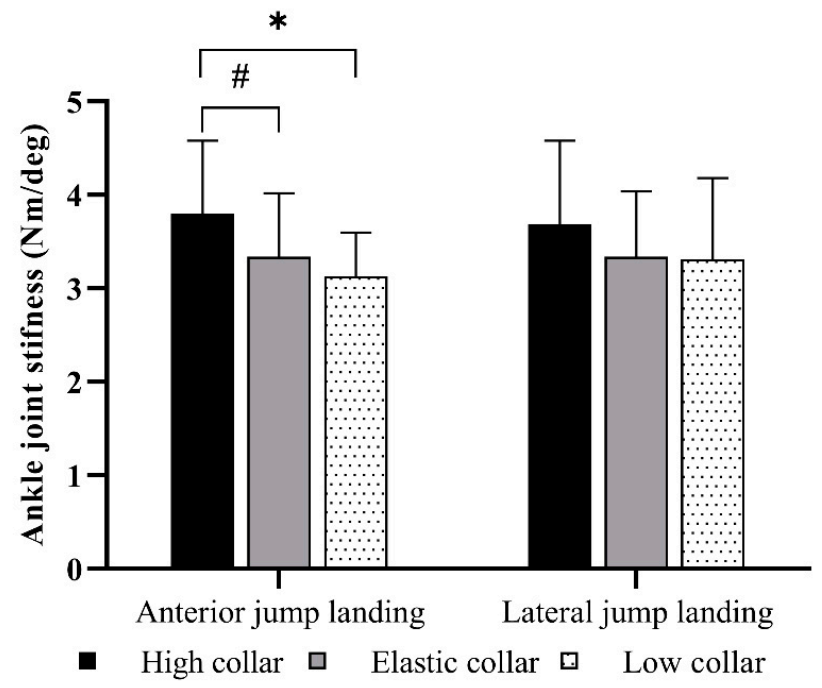

Figure 4. Ankle joint stiffness for both anterior and lateral jump landings in three shoe conditions: high collar, elastic collar, and low collar. * indicates a significant pairwise difference between the high collar and low collar; \# indicates a significant pairwise difference between the high collar and elastic collar.

\subsection{Lateral Single-Leg Jump Landing}

There were significant differences in inversion $\operatorname{ROM}\left(\mathrm{F}_{2,28}=4.344, p=0.029\right.$, Wilks's $\Lambda=0.690$, $\left.\eta p^{2}=0.658\right)$, total ROM in both sagittal $\left(\mathrm{F}_{2,28}=6.404, p=0.009\right.$, Wilks's $\left.\Lambda=0.373, \eta p^{2}=0.813\right)$ and frontal $\left(\mathrm{F}_{2,28}=6.655, p=0.006\right.$, Wilks's $\left.\Lambda=0.571, \eta p^{2}=0.846\right)$ planes, ankle joint stiffness $\left(\mathrm{F}_{2,28}=3.783\right.$, $p=0.040$, Wilks's $\left.\Lambda=0.703, \eta p^{2}=0.610\right)$, and MLSI $\left(\mathrm{F}_{2,28}=7.554, p=0.041\right.$, Wilks's $\Lambda=0.664$, $\eta \mathrm{p}^{2}=0.601$ ) between shoe conditions. Post hoc pairwise tests indicated that inversion ROM was significantly smaller for the high collar, compared to the elastic collar $(p=0.028, \mathrm{dz}=0.615)$ shoe (Table 1). The high collar resulted in a significantly smaller total ROM, compared to the low collar $(p=0.001, \mathrm{dz}=0.634)$ in the sagittal plane (Figure 3$)$, while the elastic collar resulted in a significantly larger ROM, compared to the high collar $(p=0.019, \mathrm{dz}=0.873)$ in the frontal plane (Figure 3$)$. No other pairwise differences were observed for ankle joint stiffness and MLSI (Tables 1 and 2).

\section{Discussion}

In the present study, we determined the effects of football shoes with different collar conditions on dynamic stability and ankle biomechanical characteristics during anterior and lateral single-leg jump 
landings. Our results indicate that the high collar football shoe resulted in smaller dorsiflexion ROM and total ROM in the sagittal plane during the anterior single-leg jump landing, while it also decreased inversion ROM and total ROM in the sagittal and frontal planes during the lateral single-leg jump landing. We also found that ankle joint stiffness was significantly larger for the high collar football shoe during anterior and lateral single-leg jump landings, which contradicted our original hypothesis. For dynamic stability, only MLSI showed significant differences during both landing tasks, which was greater when wearing the high collar football shoe and lesser in other conditions; this is partly consistent with our original hypothesis.

The ankle ROM during the anterior single-leg jump landing suggested that the high collar significantly constrained ankle movement, compared to the elastic and low collars. These findings are consistent with Yang et al. and Rowson et al., who reported that peak ankle dorsiflexion or total ankle ROM during a sagittal maneuver was reduced as collar height increases [13,37]. They suggested that collar height and material play an important role in influencing the flexibility and deformation of the whole shoe [13,37]. Additionally, the high collar basketball shoes with strips of plastic that are positioned at the collar's anterior and posterior to the medial and lateral malleoli showed a more restricted ROM of the ankle joint in the sagittal and frontal planes, compared to no plastic condition [16]. It is noteworthy that the elastic collar could not constrain the ankle movement, which might have been due to the low rigidity or high elasticity of the collar material. However, there was no significant change in the frontal plane's ROM. One possible reason is that our healthy participants might have had few inversion-eversion movements during the anterior single-leg jump landings, because our results detected significant differences in inversion and total ankle ROM in the frontal plane between the high and elastic collar, but not between the high and low collar during lateral single-leg jump landings. The elastic collar, similar to ankle taping, likely provides a feeling of confidence and stability $[18,24]$. This result, in our perspective, is in disagreement with a recent report that indicated that high collar basketball shoes do not restrict the peak inversion angle $\left(29.3^{\circ}\right.$ vs. $\left.28.3^{\circ}\right)$ and $\operatorname{ROM}\left(17.4^{\circ}\right.$ vs. $\left.15.2^{\circ}\right)$ in a self-initiated drop landing on an inversion platform [14]. However, our findings are supported by Richard et al., who found that a high collar football shoe effectively reduces the amount of inversion by $4.5^{\circ}\left(38.1^{\circ}\right.$ vs. $\left.42.6^{\circ}\right)$ after an inversion platform drop [17]. It is possible that a self-initiated drop landing on an inversion platform does not reach the limitation boundary of the inversion for a high collar basketball shoe. During side-step cutting, Liu et al. and Lam et al. found that the ankle inversion angle, peak inversion velocity, and total inversion ROM are reduced as collar height increases [11,12]. Therefore, there is a restricted angle for an inverted ankle joint position, which might effectively increase ankle joint stability and reduce the risk of ankle sprain injury $[11,12]$. In our study, the dorsiflexion and total sagittal ROM showed moderate-to-large effect sizes with the high collar, compared to the other collars. Therefore, the football shoe's higher collar height used in this study could constrain ankle dorsiflexion and the inversion angle during both longitude and widthwise tasks, potentially reducing the risk of ankle sprain injury.

Several prior studies have examined the effect of collar conditions on ankle kinetics. Lam et al. detected no difference from collar conditions on the ankle inversion moment during side-step cutting [12]. In addition, Yang et al. reported that high collar basketball shoes could reduce the plantarflexion moment during lay-up jumps, but not drop jumps [13]. The authors suggested that these differential findings were caused by different upper limb positions, movement patterns, and force requirements, as well as the coordination of active and antagonist muscles [13]. These findings are in agreement with our results showing either no significant change or a small effect size in the ankle inversion moment for both tasks; however, different jump maneuvers that are high-frequency and risky during practices or matches still need to be tested. Interestingly, ankle joint stiffness was significantly increased when wearing the high collar football shoe, compared to the other shoes. Theoretically, ankle joint stiffness is calculated using the change in joint moment divided by the change in joint angle [35]. Although the change in ankle moment was not measured in our study, it is possible that the enhanced ankle joint stiffness from the high collar football shoe may be due to a decrease in total ankle 
ROM in the sagittal plane. Given the primary role that joint stiffness plays in lower limb injuries [38], overuse injuries at the ankle joint might increase as collar height increases.

Our findings also suggest that MLSI is improved as the height of the football shoe collar increases. A couple of studies have examined the effect of collar height on static or dynamic postural stability $[18,39]$. However, according to previous research, adequate dorsiflexion ROM is essential for dissipating the ground reaction force [40] and has a positive influence on DPSI [30]; these findings conflict with the results of our study. However, evidence from ankle taping and bracing indicate an increased sense of confidence and stability [24]. Inconsistent findings across studies regarding the dynamic stability of ankle taping or bracing might be due to subjects with or without injury [25-28]. Furthermore, although the current study showed a significant difference in MLSI between shoe conditions during lateral single-leg jump landings, post hoc analysis indicated no pairwise difference, and small effect size. Therefore, this phenomenon still needs to be confirmed, and additional quantitative studies on DPSI are warranted.

There are some limitations to the present study. First, only healthy male college football players were recruited as subjects. Players with functional ankle instability may have different responses to shoe collar conditions, especially for DPSI. Second, it should be noted that our current findings were limited to anterior and lateral single-leg jump landings. Future studies should investigate other typical movements that have high injury risk, such as side-step cutting. Third, different types of shoes may have different mass, which could affect biomechanical responses. A better-controlled experiment is to match the shoe mass across conditions. Fourth, the long-term effect of shoe collar conditions on the incidence of lower limb injuries has yet to be examined. Long-term prospective studies are needed. Finally, the current study only focused on the biomechanical changes at the ankle joint, while knee and hip joint kinematics and kinetics and muscle activity data were not collected.

\section{Conclusions}

In the current study, the association between the collar condition of football shoes and ankle biomechanics and dynamic postural stability was analyzed. Ankle joint ROM and MLSI during a single-leg jump landing were reduced and improved as the height of the collar increased, respectively. In addition, higher ankle joint stiffness was found for the high collar, compared to the low collar football shoe. Ankle biomechanics and MLSI information from different collar types may be useful in designing football footwear and implementing training. Future prospective investigations are warranted to determine the influence of different shoe collar heights, ankle kinematics/kinetics, and DPSI on lower extremity risks.

Author Contributions: This paper is a result of the collaboration of all authors. All authors have previous experience in sport biomechanics that was shared in order to reach the results discussed in this paper. Conceptualization: Y.T. and Z.W.; data curation: Z.W. and Y.Z.; formal analysis: Y.T. and J.P.; funding acquisition: Y.L.; investigation: Y.Z.; methodology: Y.Z. and S.W.; project administration: Y.L. and J.P.; resources: Y.T. and Y.L.; software: Z.W. and J.P.; supervision: Y.L.; validation: S.Z., S.W., and Y.L.; visualization: Z.W.; writing一original draft: Y.T.; writing - review and editing: S.Z., Y.L., and J.P. All authors have read and agreed to the published version of the manuscript.

Funding: This research was funded by the National Natural Science Foundation of China (No. 11932013) and the National Key Research and Development Program of China (2018YFF0300501).

Acknowledgments: The authors thank all participants for their contributions.

Conflicts of Interest: The authors declare no conflicts of interest.

\section{References}

1. Walls, R.J.; Ross, K.A.; Fraser, E.J.; Hodgkins, C.W.; Smyth, N.A.; Egan, C.J.; Calder, J.; Kennedy, J.G. Football injuries of the ankle: A review of injury mechanisms, diagnosis and management. World J. Orthop. 2016, 7, 8-19. [CrossRef] [PubMed]

2. Ekstrand, J. Epidemiology of football injuries. Lancet 2008, 23, 73-77. [CrossRef] 
3. Pfirrmann, D.; Herbst, M.; Ingelfinger, P.; Simon, P.; Tug, S. Analysis of injury incidences in male professional adult and elite youth soccer players: A systematic review. J. Athl. Train. 2016, 51, 410-424. [CrossRef] [PubMed]

4. Wong, P.; Hong, Y. Soccer injury in the lower extremities. Br. J. Sports Med. 2005, 39, 473-482. [CrossRef]

5. Hwang-Bo, K.; Joo, C.H. Analysis of injury incidences in the Korea national men's soccer teams. J. Exerc. Rehabilit. 2019, 15, 861-866. [CrossRef]

6. Dvorak, J.; Junge, A.; Derman, W.; Schwellnus, M. Injuries and illnesses of football players during the 2010 FIFA World Cup. Br. J. Sports Med. 2011, 45, 626-630. [CrossRef]

7. Hertel, J.; Corbett, R.O. An updated model of chronic ankle instability. J. Athl. Train. 2019, 54, 572. [CrossRef]

8. Torg, J.S.; Quedenfeld, T. Effect of shoe type and cleat length on incidence and severity of knee injuries among high school football players. Res. Q. 1971, 42, 203-211.

9. Queen, R.M.; Charnock, B.L.; Garrett, W.E.; Hardaker, W.M.; Sims, E.L.; Moorman, C.T. A comparison of cleat types during two football-specific tasks on FieldTurf. Br. J. Sports Med. 2008, 42, 278-284. [CrossRef]

10. Torg, J.S.; Stilwell, G.; Rogers, K. The effect of ambient temperature on the shoe-surface interface release coefficient. Am. J. Sports Med. 1996, 24, 79-82. [CrossRef]

11. Liu, H.; Wu, Z.; Lam, W.K. Collar height and heel counter-stiffness for ankle stability and athletic performance in basketball. Res. Sports Med. 2017, 25, 209-218. [CrossRef] [PubMed]

12. Lam, G.W.; Park, E.J.; Lee, K.K.; Cheung, J.T. Shoe collar height effect on athletic performance, ankle joint kinematics and kinetics during unanticipated maximum-effort side-cutting performance. J. Sports Sci. 2015, 33, 1738-1749. [CrossRef] [PubMed]

13. Yang, Y.; Fang, Y.; Zhang, X.; He, J.; Fu, W. Does shoe collar height influence ankle joint kinematics and kinetics in sagittal plane maneuvers? J. Sports Sci. Med. 2017, 16, 543-550. [PubMed]

14. Fu, W.; Fang, Y.; Liu, Y.; Hou, J. The effect of high-top and low-top shoes on ankle inversion kinematics and muscle activation in landing on a tilted surface. J. Foot Ankle Res. 2014, 7, 14. [CrossRef]

15. Brizuela, G.; Llana, S.; Ferrandis, R.; Garcia-Belenguer, A.C. The influence of basketball shoes with increased ankle support on shock attenuation and performance in running and jumping. J. Sports Sci. 1997, 15, 505-515. [CrossRef]

16. Thacker, S.B.; Stroup, D.F.; Branche, C.M.; Gilchrist, J.; Weitman, E.A. The prevention of ankle sprains in sports. a systematic review of the literature. Am. J. Sports Med. 1999, 27, 753-760. [CrossRef]

17. Sherman, N.W.; Daniel, M. Effects of high-top and low-top shoes on ankle inversion. J. Phys. Educ. Recreat. Dance 2002, 73, 6. [CrossRef]

18. Pizac, D.A.; Swanik, C.B.; Glutting, J.J.; Kaminski, T.W. Evaluating postural control and ankle laxity between taping and high-top cleats in high school football players. J. Sport Rehabilit. 2016, 27, 1-26. [CrossRef]

19. Grimmer, K.; Williams, J. Injury in junior Australian Rules footballers. J. Sci. Med. Sport 2003, 6, 328-338. [CrossRef]

20. Jones, D.; Louw, Q.; Grimmer, K. Recreational and sporting injury to the adolescent knee and ankle: Prevalence and causes. Aust. J. Physiother. 2000, 46, 179-188. [CrossRef]

21. McGuine, T.A.; Greene, J.J.; Best, T.; Leverson, G. Balance as a predictor of ankle injuries in high school basketball players. Clin. J. Sport Med. 2000, 10, 239-244. [CrossRef] [PubMed]

22. Willems, T.M.; Witvrouw, E.; Delbaere, K.; Mahieu, N.; De Bourdeaudhuij, I.; De Clercq, D. Intrinsic risk factors for inversion ankle sprains in male subjects: A prospective study. Am. J. Sports Med. 2005, 33, 415-423. [CrossRef] [PubMed]

23. Lord, S.R.; Bashford, G.M.; Howland, A.; Munroe, B.J. Effects of shoe collar height and sole hardness on balance in older women. J. Am. Geriatr. Soc. 1999, 47, 681-684. [CrossRef] [PubMed]

24. Simon, J.; Donahue, M. Effect of ankle taping or bracing on creating an increased sense of confidence, stability, and reassurance when performing a dynamic-balance task. J. Sport Rehabilit. 2013, 22, 229-233. [CrossRef] [PubMed]

25. Fayson, S.D.; Needle, A.R.; Kaminski, T.W. The effects of ankle Kinesio taping on ankle stiffness and dynamic balance. Res. Sports Med. 2013, 21, 204-216. [CrossRef] [PubMed]

26. Lee, B.G.; Lee, J.H. Immediate effects of ankle balance taping with kinesiology tape on the dynamic balance of young players with functional ankle instability. Technol. Health Care 2015, 23, 333-341. [CrossRef] 
27. Papadopoulos, E.S.; Nikolopoulos, C.S.; Athanasopoulos, S. The effect of different skin-ankle brace application pressures with and without shoes on single-limb balance, electromyographic activation onset and peroneal reaction time of lower limb muscles. Foot 2008, 18, 228-236. [CrossRef]

28. Persson, U.M.; Arthurs, C. Dynamic postural stability in gaelic football players during a single leg drop-landing, a comparison of ankle tape and lace-up brace. Br. J. Sport Med. 2011, 45, 362. [CrossRef]

29. Bowser, B.J.; Rose, W.C.; McGrath, R.; Salerno, J.; Wallace, J.; Davis, I.S. Effect of footwear on dynamic stability during single-leg jump landings. Int. J. Sports Med. 2017, 38, 481-486. [CrossRef]

30. Wikstrom, E.A.; Tillman, M.D.; Smith, A.N.; Borsa, P.A. A new force-plate technology measure of dynamic postural stability: The dynamic postural stability index. J. Athl. Train 2005, 40, 305-309.

31. Zhang, S.; Pan, J.; Li, L. Non-linear changes of lower extremity kinetics prior to gait transition. J. Biomech. 2018, 77, 48-54. [CrossRef] [PubMed]

32. Pan, J.; Liu, C.; Zhang, S.; Li, L. Tai chi can improve postural stability as measured by resistance to perturbation related to upper limb movement among healthy older adults. Evid. Based Complement. Altern. 2016, 2016, 9710941. [CrossRef] [PubMed]

33. Sell, T.C. An examination, correlation, and comparison of static and dynamic measures of postural stability in healthy, physically active adults. Phys. Ther. Sport 2012, 13, 80-86. [CrossRef] [PubMed]

34. Williams, V.J.; Nagai, T.; Sell, T.C.; Abt, J.P.; Rowe, R.S.; McGrail, M.A.; Lephart, S.M. Prediction of dynamic postural stability during single-leg jump landings by ankle and knee flexibility and strength. J. Sport Rehabilit. 2016, 25, 266-272. [CrossRef] [PubMed]

35. Farley, C.T.; Houdijk, H.H.P.; Ciska, V.S.; Ciska, V.S.; Micky, L. Mechanism of leg stiffness adjustment for hopping on surfaces of different stiffnesses. J. Appl. Physiol. 1998, 85, 1044-1055. [CrossRef]

36. Wikstrom, E.A.; Tillman, M.D.; Borsa, P.A. Detection of dynamic stability deficits in subjects with functional ankle instability. Med. Sci. Sports Exerc. 2005, 37, 169-175. [CrossRef]

37. Rowson, S.; McNally, C.; Duma, S.M. Can footwear affect achilles tendon loading? Clin. J. Sport Med. 2010, 20, 344-349. [CrossRef]

38. Hamill, J.; Moses, M.; Seay, J. Lower extremity joint stiffness in runners with low back pain. Res. Sports Med. 2007, 17, 260-273. [CrossRef]

39. Fong, C.M.; Blackburn, J.T.; Norcross, M.F.; McGrath, M.; Padua, D.A. Ankle-dorsiflexion range of motion and landing biomechanics. J. Athl. Train. 2011, 46, 5-10. [CrossRef]

40. Debusk, H.; Hill, C.M.; Chander, H.; Knight, A.C.; Babski-Reeves, K. Influence of military workload and footwear on static and dynamic balance performance. Int. J. Ind. Ergonom. 2018, 64, 51-58. [CrossRef] 